Article

\title{
Microstructure and Properties of Spark Plasma Sintered Aluminum Containing 1 wt.\% SiC Nanoparticles
}

\author{
Ismaila Kayode Aliyu, Nouari Saheb *, Syed Fida Hassan and Nasser Al-Aqeeli \\ Department of Mechanical Engineering, Center of Research Excellence in Nanotechnology, \\ King Fahd University of Petroleum and Minerals, Dhahran 31261, Saudi Arabia; \\ E-Mails: aismaila@kfupm.edu.sa (I.K.A.); sfhassan@kfupm.edu.sa (S.F.H.); \\ naqeeli@kfupm.edu.sa (N.A.-A.) \\ * Author to whom correspondence should be addressed; E-Mail: nouari@kfupm.edu.sa; \\ Tel.: +966-13-860-7529; Fax: +966-13-860-2949.
}

Academic Editor: Hugo F. Lopez

Received: 19 November 2014 / Accepted: 6 January 2015 / Published: 12 January 2015

\begin{abstract}
The low hardness and strength of aluminum, which limits its use in many industrial applications, could be increased through the addition of nanoparticles. However, the appropriate processing method and parameters should be carefully selected in order to achieve the desired improvement in properties. In this work, aluminum was reinforced with low weight fraction (1 wt.\%) of SiC nanoparticles and consolidated through spark plasma sintering. The effect of processing parameters on the densification, microstructure, and properties of the processed material was investigated. Field Emission Scanning Electron Microscope (FE-SEM) equipped with Energy Dispersive X-ray Spectroscopy (EDS) facility was used to characterize the microstructure and analyze the reinforcement's distribution in sintered samples. Phases present were characterized through X-ray diffraction (XRD). A densimeter and a digital microhardness tester were used to measure the density and hardness, respectively. Compressive tests were performed using universal testing machine. A fully dense Al-1 wt.\% SiC sample was obtained. Analysis of density and hardness values showed that the influence of applied pressure was more pronounced than heating rate while the influence of sintering temperature was more significant than sintering time. Within the range of parameters used, the highest values of the characterized properties were obtained at a sintering temperature of $600{ }^{\circ} \mathrm{C}$, sintering time of $10 \mathrm{~min}$, pressure of $50 \mathrm{MPa}$, and heating rate of $200^{\circ} \mathrm{C} / \mathrm{min}$.
\end{abstract}


Keywords: aluminum; $\mathrm{SiC}$ nanoparticles; microstructure; microhardness; density; spark plasma sintering; compressive strength

\section{Introduction}

The need for metallic materials with better physical and mechanical properties to satisfy current applications in aerospace and automotive industries has led to the development of metal matrix composites (MMCs) [1,2]. MMCs have excellent properties, such as high fatigue strength, high specific modulus, stability at elevated temperatures, lower coefficient of thermal expansion, high specific strength, and better wear resistance [3,4]. Metal Matrix Nanocomposites (MMNCs), where at least one of the constituent phases has a dimension less than $100 \mathrm{~nm}$, have been developed and their properties were evaluated and found to be better than the properties of metal matrix composites [5-9]. However, there are several challenges associated with the development of MMNCs. These include agglomeration of the nano-size reinforcement in the matrix [10-12], grain growth of the matrix [13,14], poor interfacial bonding [9,13], and high cost [9]. Liquid-state processing techniques suffer from the poor wettability of the reinforcement with the liquid matrix [15-19]. In addition, they may lead to the formation of unwanted and brittle phases like $\mathrm{Al}_{4} \mathrm{C}_{3}$ and $\mathrm{Si}$, in the case of $\mathrm{Al}-\mathrm{SiC}$ composites [16,20], due to processing at relatively high temperatures. However, solid-state processing techniques have been proven to be effective in overcoming most of the challenges associated with processing MMNCs. Mechanical milling (ball milling) is the dominant method used to synthesize nanocomposite powders with uniform distribution of hard particulate phase into the relatively soft metal matrix [17,21]. Although mechanical milling has been proved to be successful for powders preparation, the use of consolidation techniques may deteriorate the properties of the bulk composite. Several nonconventional sintering techniques, such as cold isostatic pressing (CIP), hot isostatic pressing (HIP), hot pressing, hot extrusion and hot rolling have been applied to consolidate nanocomposites [13,22]. However, these conventional techniques have limitations, such as long sintering time and high temperature that lead to grain growth. Recently, spark plasma sintering (SPS), a non-conventional sintering process, has emerged as one of the best methods to consolidate nanocomposite powders. The process involves simultaneous application of pulsed DC current and uniaxial pressure. With SPS, high heating rates can be achieved [23], and sintering can be performed at relatively low temperatures for short sintering times. This enables the synthesis of fully dense materials [24]. The process does not require the use of binders and pre-compaction. Khalil [24] sintered Al 6061 alloy using HIP, microwave sintering (MW), SPS and furnace sintering (FS) and found that the highest density (100\%) was obtained for samples sintered by SPS. Nanoparticle reinforcements such as $\mathrm{SiC}, \mathrm{TiC}, \mathrm{Al}_{4} \mathrm{C}_{3}, \mathrm{WC}, \mathrm{TaC}, \mathrm{TiB}_{2}, \mathrm{AlB}_{2}, \mathrm{AlN}$, and $\mathrm{Al}_{2} \mathrm{O}_{3}$ have been used with metals like $\mathrm{Al}, \mathrm{Co}$, $\mathrm{Cu}, \mathrm{Fe}, \mathrm{Mg}, \mathrm{Mo}, \mathrm{Ni}, \mathrm{Ti}$ and $\mathrm{W}$ to produce MMNCs $[19,25]$. It is know that aluminum is an ideal candidate for the development of metal matrix nanocomposites because of its excellent properties, such as lightweight, low melting temperature [26], high corrosion resistance and great formability. This permitted its wide application in aerospace, high temperature and pressure need, turbines, aircraft, building materials, desalination machined components and automobiles for quite a long time. Properties of aluminum can be improved by introducing nano-reinforcements such as $\mathrm{SiC}$, which has excellent 
mechanical properties, including high hardness, strength, modulus of elasticity, wear resistance, oxidation resistance and corrosion resistance [17,27,28]. $\mathrm{SiC}$ is suitable for reinforcing aluminum because of its thermodynamic stability and good wettability with Al [27-29]. Al-based nanocomposites have successfully been synthesized by mechanical milling and spark plasma sintering [13,30-32]. The development of Al-SiC nanocomposites has not been fully explored despite the potential of $\mathrm{SiC}$ nanoparticles to improve the properties of $\mathrm{Al}$ matrix. Al-SiC nanocomposites have been consolidated through SPS, however, the effect of process parameters on the microstructure and properties was not fully investigated. The objective of the present work is to investigate the influence of heating rate, compacting pressure, sintering time, and sintering temperature on the microstructure and properties of aluminum reinforced with low weight fraction (1 wt.\%) of SiC nanoparticles.

\section{Results and Discussion}

Figure 1 shows FE-SEM micrographs of as-received Al powder and SiC nanopowder. The aluminum powder, as seen in Figure 1a, consists of particles with spherical, elongated, and irregular shapes. Analysis of its particle size distribution showed that $76.6 \%$ of particles have particle size less than $38 \mu \mathrm{m}$; and the maximum particle size was $53 \mu \mathrm{m}$. SiC nanopowder, Figure 1b, consists of particles with irregular shapes but close to spherical with average particle size of $50 \mathrm{~nm}$. SiC nanoparticles appears agglomerated because of their small particle size. More information on powders' characteristics was presented elsewhere [4].

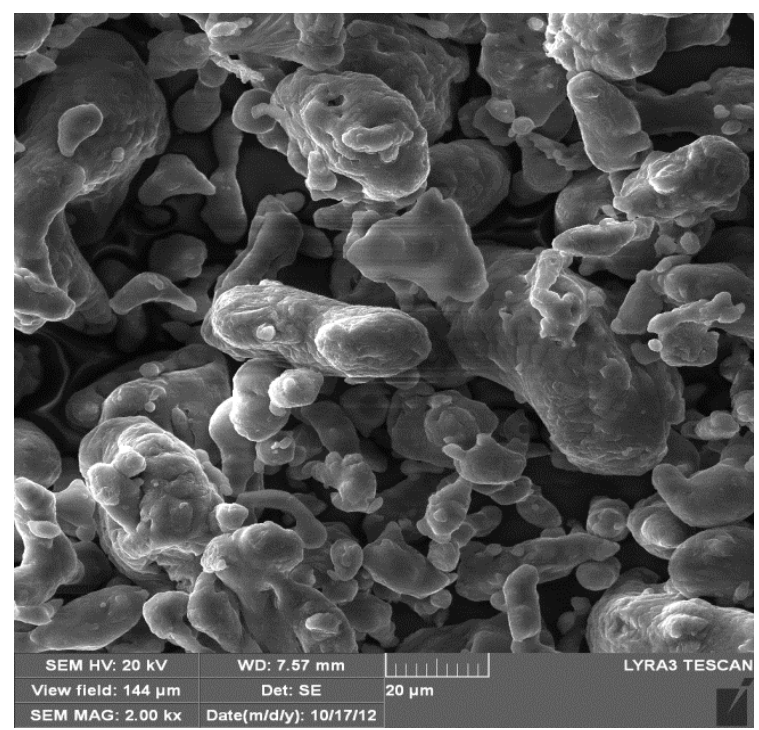

(a)

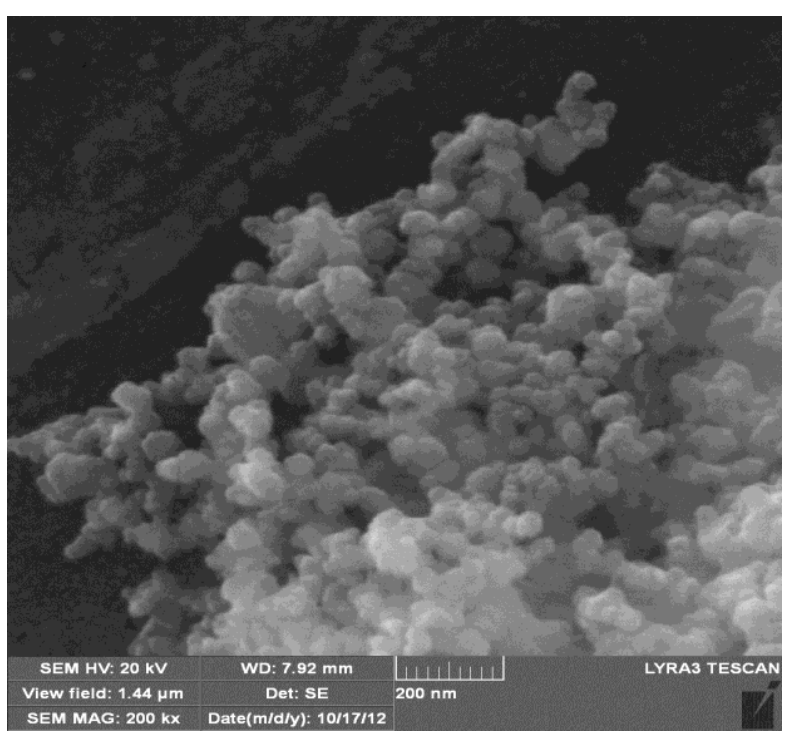

(b)

Figure 1. SEM micrographs of as received (a) Al and (b) SiC powders [4].

The SiC nanoparticles were uniformly dispersed in the aluminum powder through ball milling for $24 \mathrm{~h}$. Typical XRD spectra of pure un-milled aluminum, Al-1wt.\% SiC milled for $24 \mathrm{~h}$, and Al-1wt.\% $\mathrm{SiC}$ sintered at $600{ }^{\circ} \mathrm{C}$ for $10 \mathrm{~min}$ using a pressure of $50 \mathrm{MPa}$ and heating rate of $200{ }^{\circ} \mathrm{C} / \mathrm{min}$ are presented in Figure 2. It can be clearly seen that milling for $24 \mathrm{~h}$ led to the decrease of the intensity and broadening of peaks of the aluminum matrix phase [22,25,31]. This is due to the impact and shear forces of milling media which induces crystalline defects such as stacking faults and dislocations in the grains 
of the powder [33]. Hence stored energy of the powder grains increase up to a critical value beyond which sub-grains and nano-grains are formed [32]. Sintering increased the intensity and reduced the broadening of peaks because of grain growth. It is important to note here that peaks of the aluminum phase in the sintered sample remained broader and had less intensity compared with peaks of the raw aluminum powder. The crystallite sizes of the aluminum matrix in the milled and sintered samples, calculated using Williamson-Hall method [6,20,31], were 140 and $298 \mathrm{~nm}$, respectively. This shows marginal grain growth because of the high sinterability attributed to the SPS process [34]. A fully densified sample was obtained in relatively short sintering time of $10 \mathrm{~min}$. On the other, XRD spectra did not reveal the presence of phases other than the aluminum matrix [25,32,35]. More details on the synthesis and characterizations of samples were reported elsewhere [4].

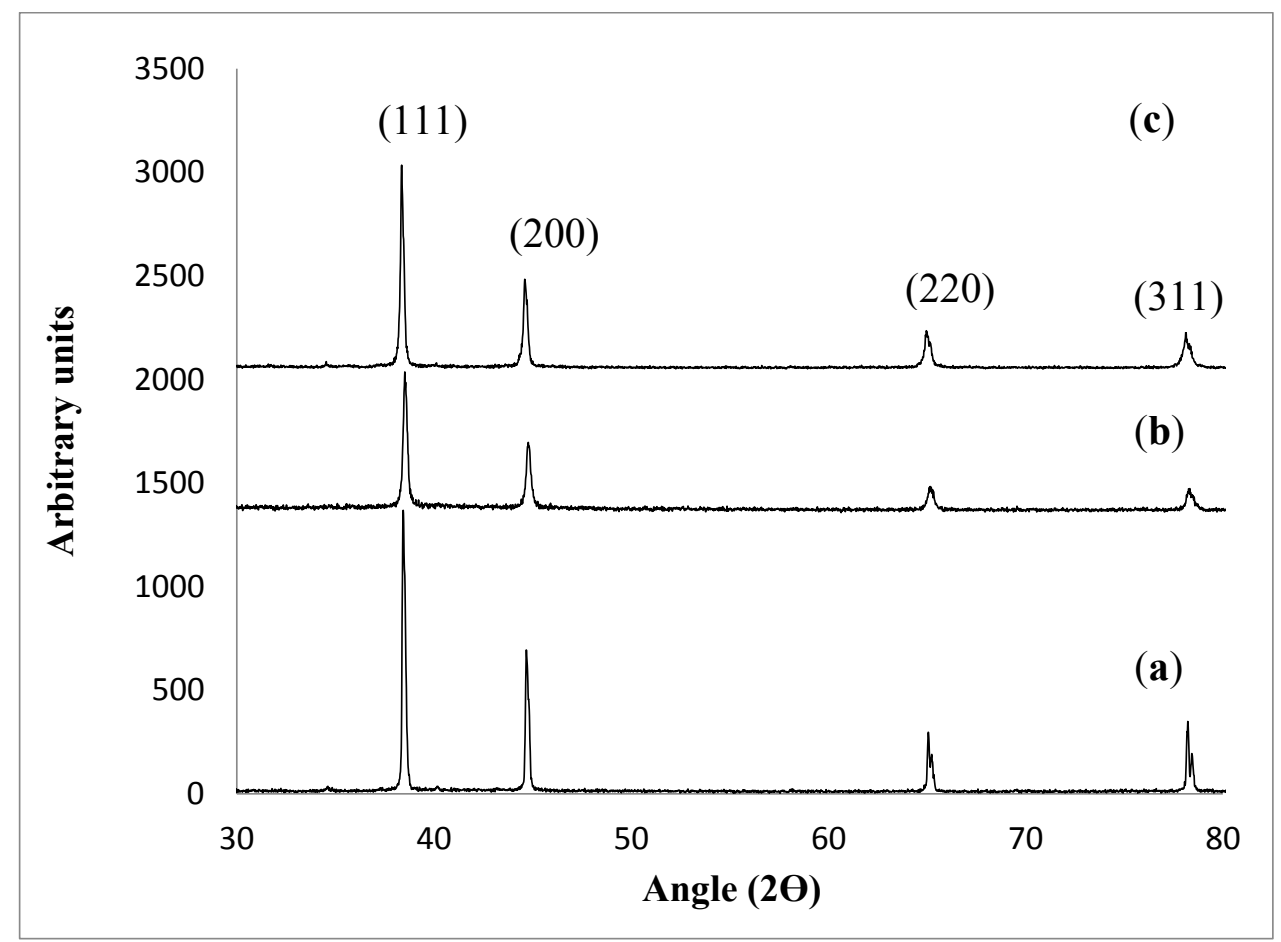

Figure 2. X-ray diffraction spectra of (a) pure Al, Al-1wt\% SiC sample (b) milled for $24 \mathrm{~h}$ and (c) sintered at $600{ }^{\circ} \mathrm{C}$ for 10 min using a pressure of $50 \mathrm{MPa}$ and heating rate of $200{ }^{\circ} \mathrm{C} / \mathrm{min}$.

The relative density and microhardness, as function of heating rate and pressure, of samples sintered at $550{ }^{\circ} \mathrm{C}$ for $5 \mathrm{~min}$ are presented in Figure 3. The increase in pressure from 20 to $50 \mathrm{MPa}$ resulted in tremendous improvement in the relative density from 87.4 to $95 \%$ as can be seen in Figure $3 \mathrm{a}$. The rate of this change, at lower pressure range, was higher than that at higher pressure. Such behavior was observed by other researchers [23,36,37]. In spark plasma sintered pure Mo [36], pressure rise between 29 and $67 \mathrm{MPa}$ enhanced densification till a marginal value was reached at $57 \mathrm{MPa}$. Figure 3a shows that heating rate has marginal effect on powder densification because the increase in heating rate from 100 to $300{ }^{\circ} \mathrm{C} / \mathrm{min}$, at most sintering pressures, had negligible effect on densification. At a heating rate of $300{ }^{\circ} \mathrm{C} / \mathrm{min}$, the increase in pressure from 35 to $50 \mathrm{MPa}$, only led to very small increase in density (less than 1\%). From the analysis of densification results, one may conclude that heating rate and sintering pressure of $300{ }^{\circ} \mathrm{C} / \mathrm{min}$ and $35 \mathrm{MPa}$, respectively, are suitable values for these sintering 
parameters. However, as can be seen in Figure 3a, sintering using a heating rate of $200{ }^{\circ} \mathrm{C} / \mathrm{min}$ and pressure of $50 \mathrm{MPa}$ resulted in a densification very close to that obtained at $300{ }^{\circ} \mathrm{C} / \mathrm{min}$ and $35 \mathrm{MPa}$. Therefore, heating rate of $200^{\circ} \mathrm{C} / \mathrm{min}$ and pressure of $50 \mathrm{MPa}$ were selected as suitable values and kept constant to investigate the effect of sintering temperature and time.

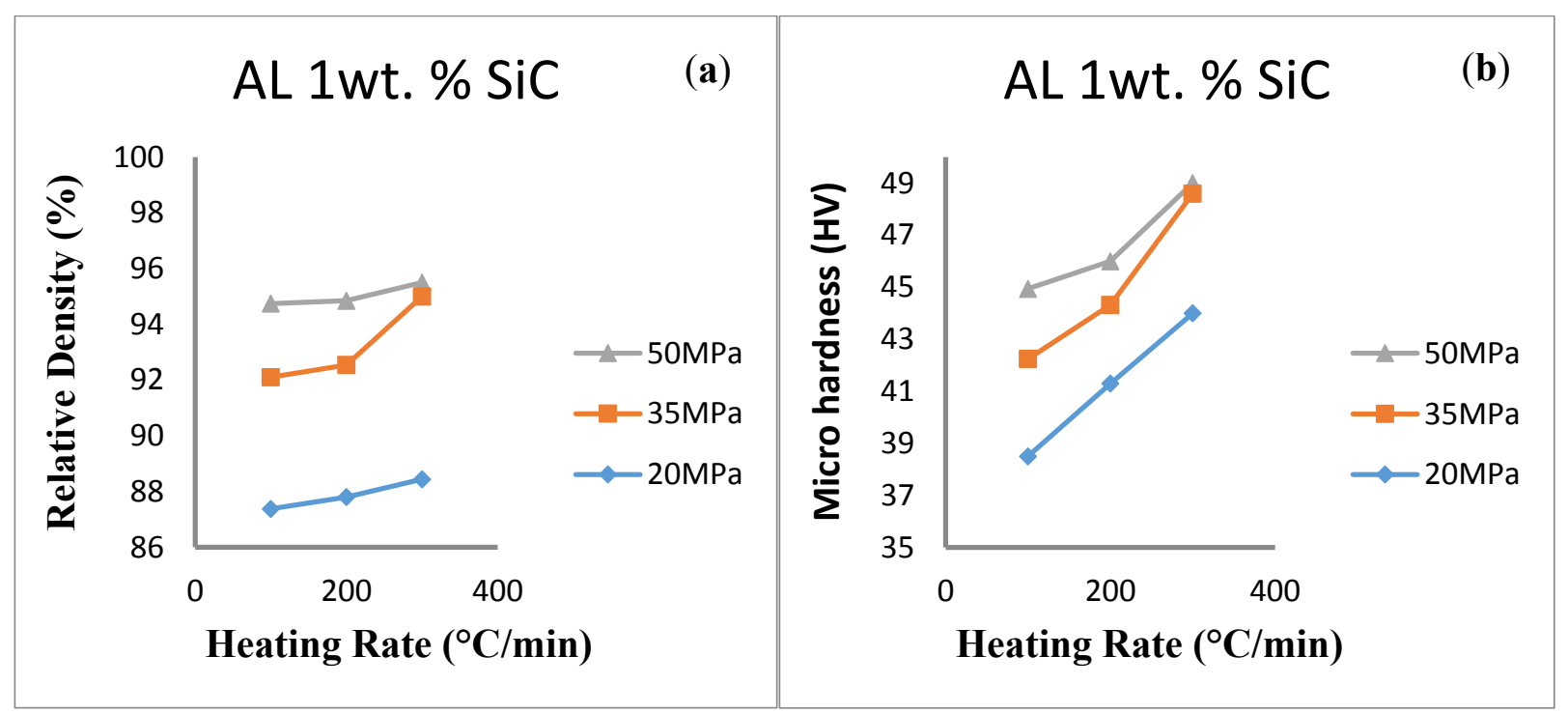

Figure 3. (a) Relative density and (b) microhardness, as function of heating rate and pressure, of samples sintered at $550{ }^{\circ} \mathrm{C}$ for $5 \mathrm{~min}$.

Overall, at fixed sintering temperature and time, the increase in sintering pressure and heating rate led to a significant increase in microhardness as can be seen in Figure $3 b$. The higher hardness values can be attributed to the higher density values. Figure 4 shows SEM micrographs of samples sintered at $550{ }^{\circ} \mathrm{C}$ for $5 \mathrm{~min}$ using heating rate of $200{ }^{\circ} \mathrm{C} / \mathrm{min}$ and pressures of 20 and $50 \mathrm{MPa}$ as seen in Figure 4a,b, respectively; and heating rate of $300{ }^{\circ} \mathrm{C} / \mathrm{min}$ and pressure of $50 \mathrm{MPa}$ as seen in Figure 4c. Figure 4a reveals the presence of large pores; and the increase of sintering pressure from 20 to $50 \mathrm{MPa}$ significantly reduced the amount and size of pores as can be noticed in Figure $4 \mathrm{~b}$. Under the applied pressure of $50 \mathrm{MPa}$, the increase in heating rate from 200 to $300{ }^{\circ} \mathrm{C} / \mathrm{min}$ did not bring about significant change in the microstructure presented in Figure 4c. The increase in pressure from 20 to $50 \mathrm{MPa}$ resulted in decrease in grain size. During sintering of pure Al [38], the authors reported the presence of linear white part between some grains, indicating the presence of aluminum oxide, and concluded that it contributes to the pinning effect and prevents grain growth. In this work, this white line was not observed. Hence, the hardness increase can be attributed to porosity decrease because of pressure increase. $\mathrm{SiC}$ is reported to prevent grain growth by pinning effect [39]. Analysis of the effect of pressure on density and hardness reveals that a pressure of $50 \mathrm{MPa}$ led to the highest density and hardness in most of the cases. Hence, $50 \mathrm{MPa}$ was considered suitable sintering pressure. Heating rate change had significant impact on microhardness, where the increase in heating rate led to the increase in microhardness. Although hardness increased with the increase in heating rate up to $300{ }^{\circ} \mathrm{C} / \mathrm{min}$, the increase in heating rate from 200 to $300^{\circ} \mathrm{C} / \mathrm{min}$ only caused little improvement in density. Therefore, heating of $200^{\circ} \mathrm{C} / \mathrm{min}$ was considered suitable for sintering. Results presented and discussed above show that using sintering pressure and heating rate of $50 \mathrm{MPa}$ and $200{ }^{\circ} \mathrm{C} / \mathrm{min}$, respectively, resulted in high 
densification and hardness. Therefore, they are kept constant to investigate the effect of changing sintering temperature and time on the microstructure and hardness.

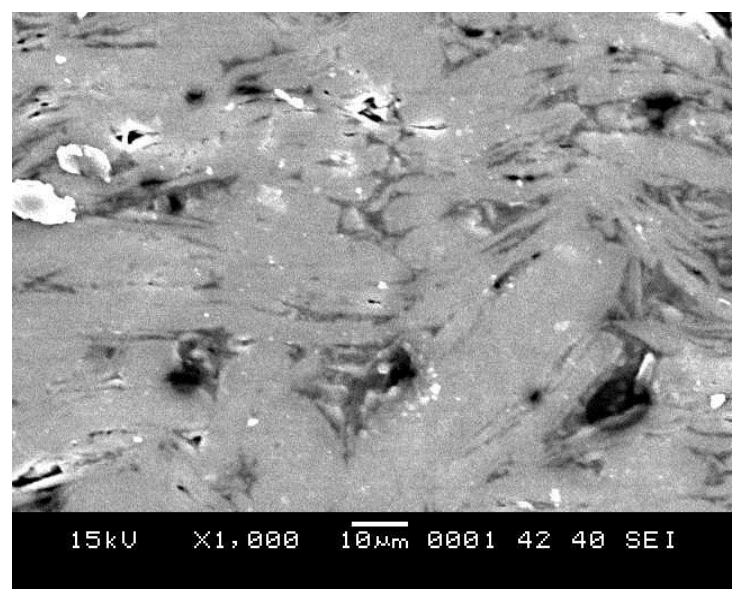

(a)

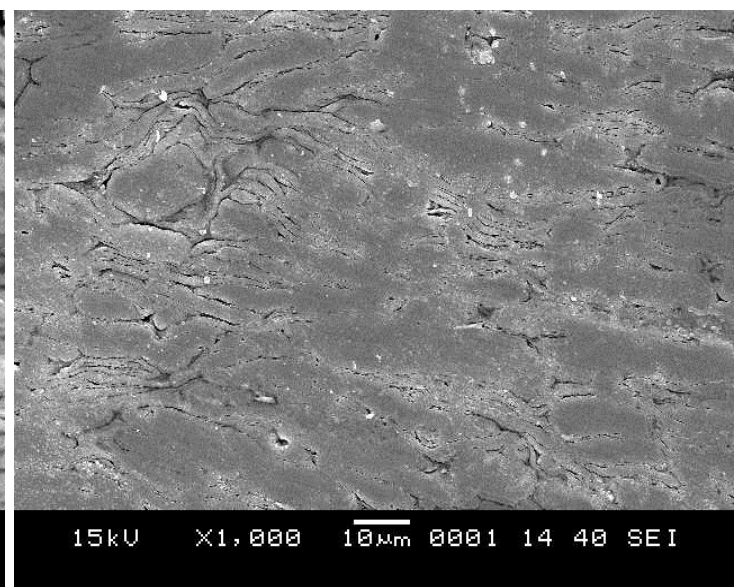

(b)

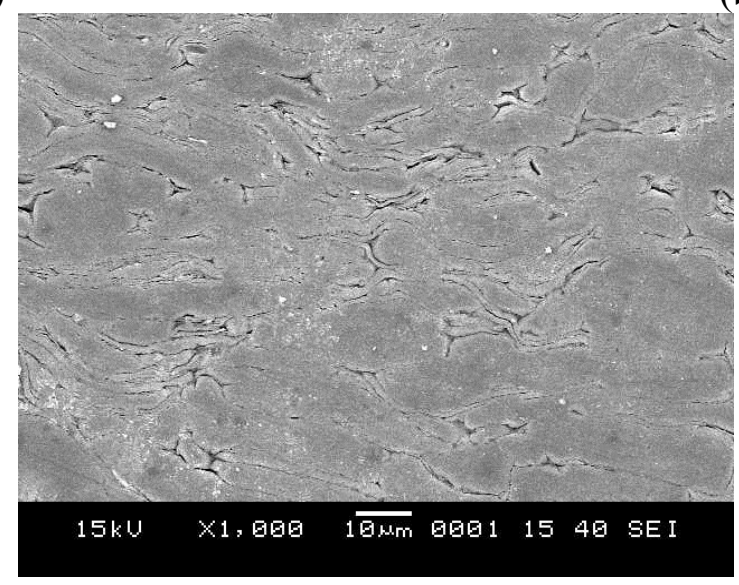

(c)

Figure 4. SEM micrographs of $\mathrm{Al}-1 \mathrm{wt} \% \mathrm{SiC}$ sintered at (a) $550{ }^{\circ} \mathrm{C}, 5 \mathrm{~min}, 200{ }^{\circ} \mathrm{C} / \mathrm{min}$, $20 \mathrm{MPa}$; (b) $550{ }^{\circ} \mathrm{C}, 5 \mathrm{~min}, 200{ }^{\circ} \mathrm{C} / \mathrm{min}, 50 \mathrm{MPa}$; (c) $550{ }^{\circ} \mathrm{C}, 5 \mathrm{~min}, 300{ }^{\circ} \mathrm{C} / \mathrm{min}, 50 \mathrm{MPa}$.

Figure 5a shows that, at a given holding time, the increase in temperature resulted in a significant increase in relative density of the sintered samples. SEM micrographs presented in Figure 6 reveal that the amount of pores decreased with the increase of sintering temperature. A limiting trend of density variation with temperature was not observed, contrary to references [40,41] where A16061 and Al2124 were spark plasma sintered between 400 and $500{ }^{\circ} \mathrm{C}$. This observation agrees with an explanation made by other researchers [42], where the relationship between temperature and density was described by

$$
\rho=s\left(\frac{T}{T_{m}}\right)+b
$$

where, $\rho$ is relative density, $s$ temperature sensitivity, $T$ and $T_{m}$ are sintering and melting temperature, respectively, and $b$ is the intercept on density axis.

The relative density increased with the increase in sintering time. Similar trend was reported by other researchers [43]. However, the rate of increase was significant at 500 and $600{ }^{\circ} \mathrm{C}$ and marginal at $550{ }^{\circ} \mathrm{C}$. This agrees with what was reported in [23]. Full densification was achieved in sample sintered at $600{ }^{\circ} \mathrm{C}$ for $10 \mathrm{~min}$, as can be seen in the microstructure presented in Figure 6c. 


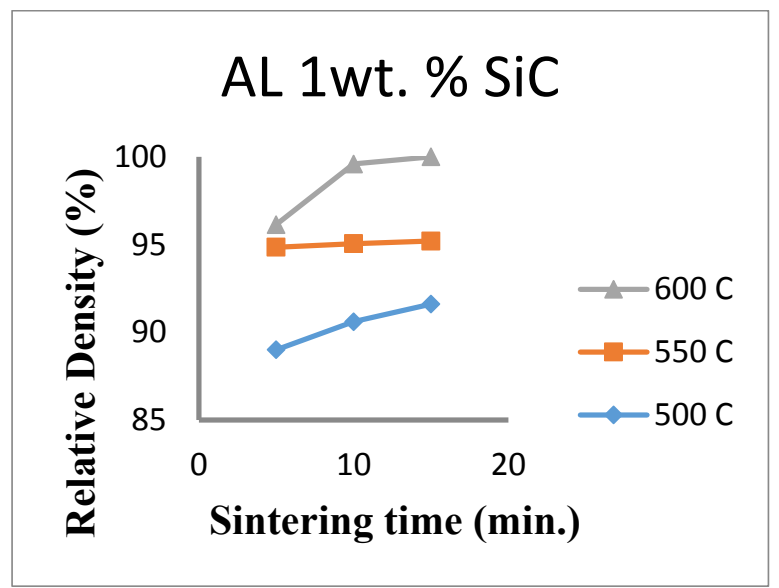

(a)

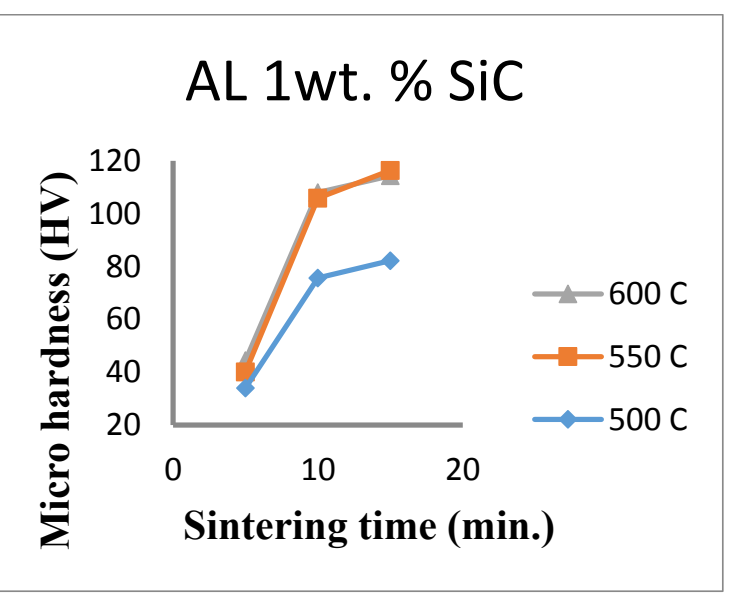

(b)

Figure 5. (a) Relative density and (b) microhardness, as function of sintering temperature and time, of samples sintered using heating rate and pressure of $200{ }^{\circ} \mathrm{C} / \mathrm{min}$ and $50 \mathrm{MPa}$, respectively.

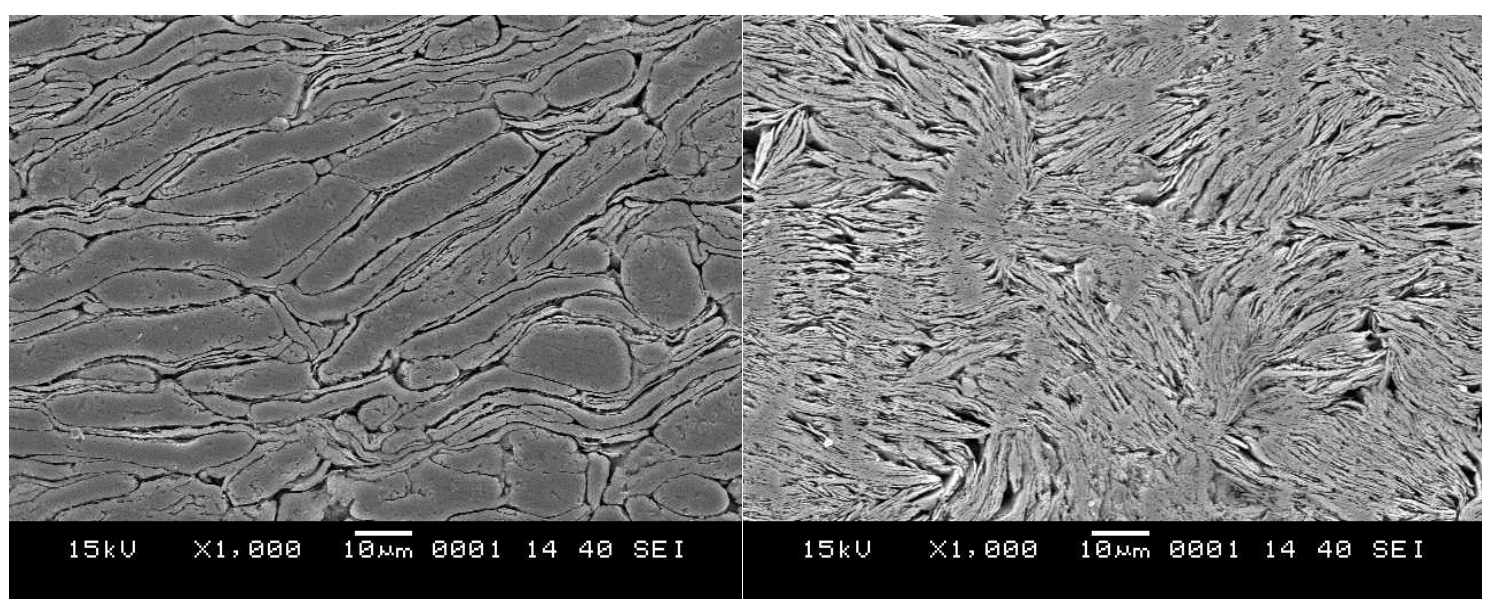

(a)

(b)

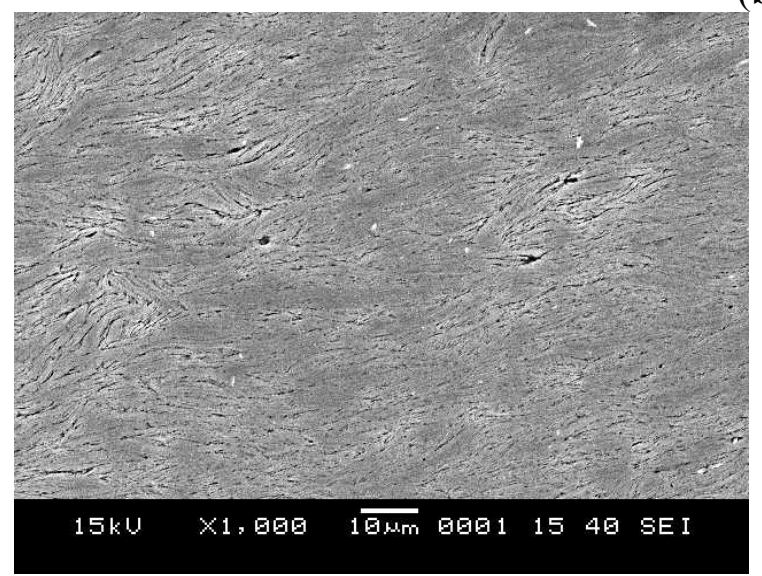

(c)

Figure 6. Microstructure of specimens sintered at (a) $500{ }^{\circ} \mathrm{C}, 200^{\circ} \mathrm{C} / \mathrm{min}, 50 \mathrm{MPa}, 5 \mathrm{~min}$; (b) $500{ }^{\circ} \mathrm{C}, 200{ }^{\circ} \mathrm{C} / \mathrm{min}, 50 \mathrm{MPa}, 10 \mathrm{~min}$; (c) $600{ }^{\circ} \mathrm{C}, 200{ }^{\circ} \mathrm{C} / \mathrm{min}, 50 \mathrm{MPa}, 10 \mathrm{~min}$.

The hardness of sintered specimens, presented in Figure 5b, increased with the increase in sintering temperature and time. This is due to better densification and reduced pores at higher sintering 
temperatures and long sintering times as can be seen in Figure 6. The increase of sintering temperature from 550 to $600{ }^{\circ} \mathrm{C}$ did not bring about further increase in hardness, however, the sample was not fully densified at $550{ }^{\circ} \mathrm{C}$ and a sintering temperature of $600{ }^{\circ} \mathrm{C}$ was necessary. A highest Vickers microhardness of 108 was obtained for samples sintered at $600{ }^{\circ} \mathrm{C}$ for $10 \mathrm{~min}$ using a heating rate and pressure of $200{ }^{\circ} \mathrm{C} / \mathrm{min}$ and $50 \mathrm{MPa}$, respectively. Analysis of the microstructure of samples shown in Figure 6 reveals that recrystallization took place at $500{ }^{\circ} \mathrm{C}$ when sintering time was increased from 5 to $10 \mathrm{~min}$ or when the sample was sintered at $600{ }^{\circ} \mathrm{C}$ for $10 \mathrm{~min}$.

Analysis of density and hardness values presented in Figures 3 and 5 shows that the influence of applied pressure was more pronounced than heating rate while the influence of sintering temperature was more significant than sintering time.

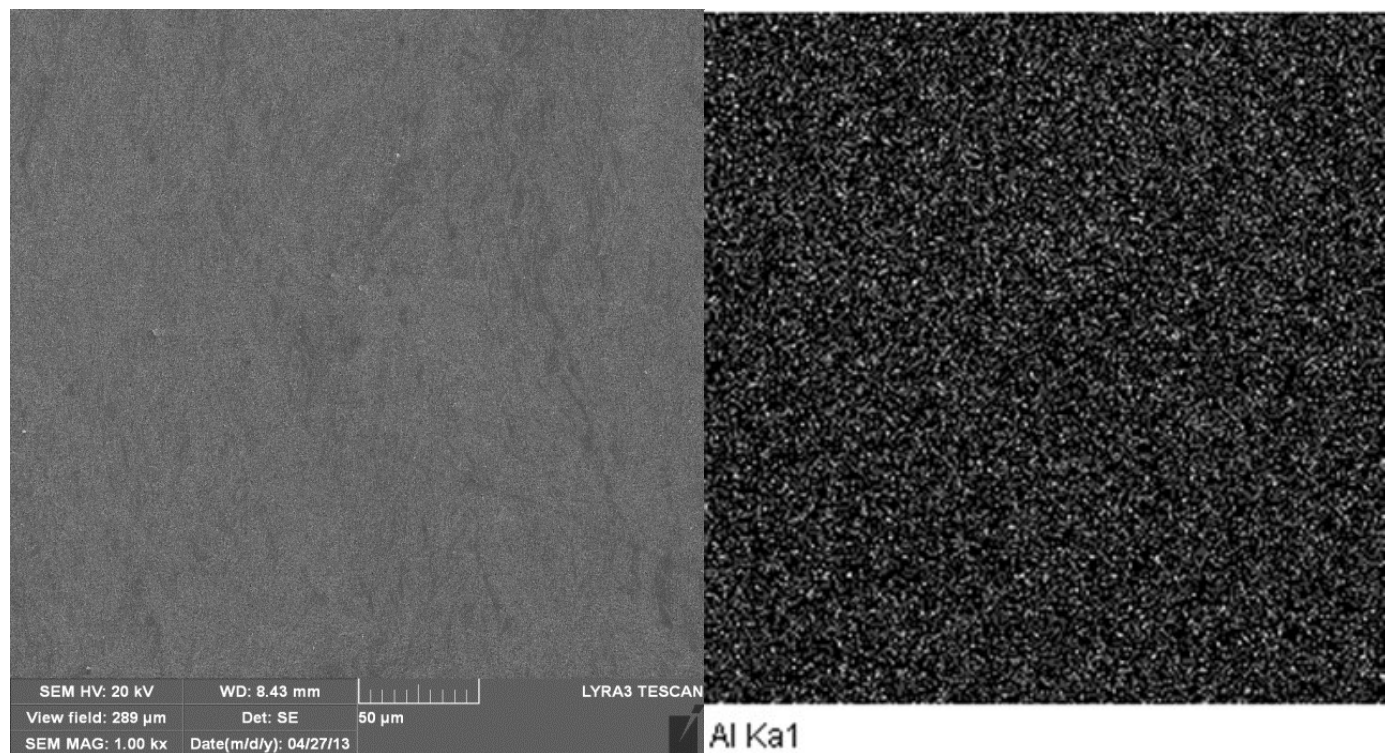

(a)

(b)

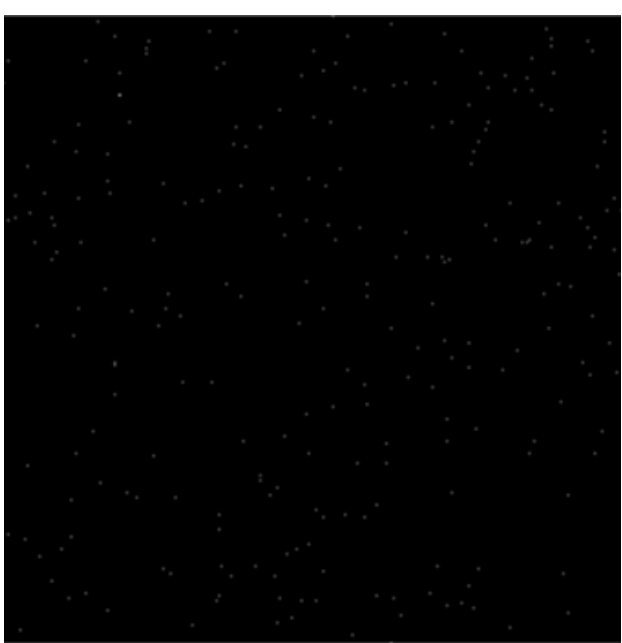

Si Ka1

(c)

Figure 7. (a) SEM micrograph and corresponding X-ray mapping of (b) Al and (c) Si of specimen sintered at $600{ }^{\circ} \mathrm{C}$ for $10 \mathrm{~min}$ using $50 \mathrm{MPa}$ and $200{ }^{\circ} \mathrm{C} / \mathrm{min}$. 
A typical SEM micrograph and corresponding X-ray mapping of $\mathrm{Al}$ and $\mathrm{Si}$ elements of specimen sintered at $600{ }^{\circ} \mathrm{C}$ for $10 \mathrm{~min}$ using $50 \mathrm{MPa}$ and $200{ }^{\circ} \mathrm{C} / \mathrm{min}$, are presented in Figure 7. It reveals a free pore microstructure, Figure $7 \mathrm{a}$, and homogenous dispersion of $\mathrm{SiC}$ particles, Figure 7c. This confirms that the uniform distribution of $\mathrm{SiC}$ particles achieved with milling time of $24 \mathrm{~h}$ [4] was maintained in the sintered specimen.

The compressive properties of sample sintered using a pressure of $50 \mathrm{MPa}$, heating rate of $200{ }^{\circ} \mathrm{C} / \mathrm{min}$, sintering temperature of $550^{\circ} \mathrm{C}$, and sintering time of $15 \mathrm{~min}$ were measured and compared with those estimated theoretically. The sample's compressive strength was found to be equal to $312 \mathrm{MPa}$. This is equivalent to an increase of $74 \%$ compared to pure aluminum. The SiC nanoparticles were incorporated in the aluminum matrix through ball milling which leads not only to the uniform distribution of SiC particles but also to the reduction of the matrix grain size [4]. Therefore, it is believed that the increase in strength is due to grain size reduction (Hall Petch theory), Orowan strengthening, increase in dislocations' density, load transfer from the matrix to the reinforcement, and strain gradient [44-47]. A theoretical value of $278 \mathrm{MPa}$ was obtained, for the sample's compressive strength, using combined Orowan and Hall Petch theory [48]. This value is lower than the value of $312 \mathrm{MPa}$ measured experimentally. It is believed that this underestimation is due to some strengthening mechanisms (e.g., strain gradient strengthening, etc.) not taken into account in the theory. SEM micrographs of fractured surfaces, shown in Figure 8, reveals that brittle fracture was dominant. In addition, fractured surfaces reveal that the sample was fully sintered unlike what was observed by other researchers [49], where original powder morphology was observed on fractured surface of pure $\mathrm{Al}$ sintered at $550{ }^{\circ} \mathrm{C}$.

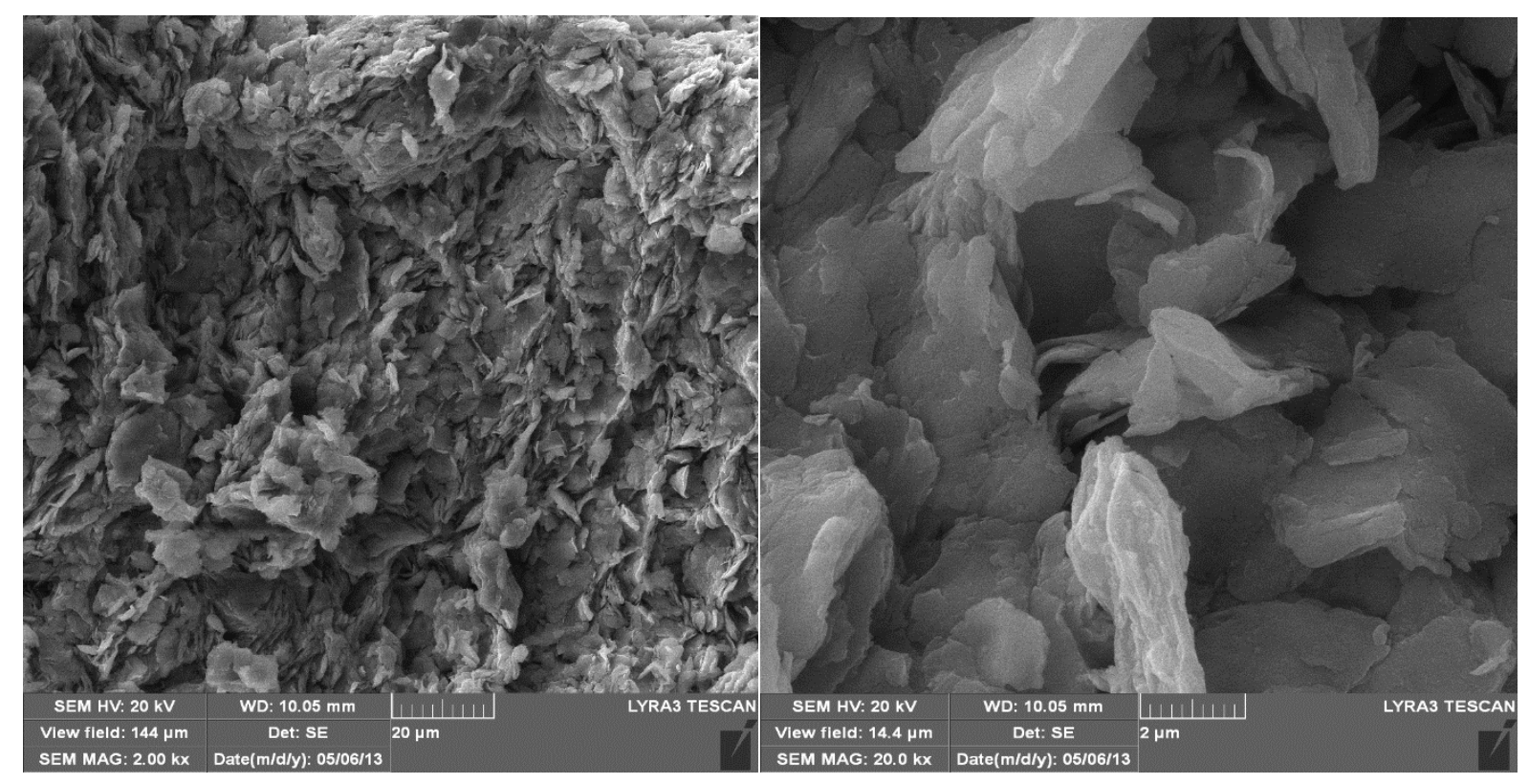

(a)

(b)

Figure 8. SEM micrographs of fractured surfaces (a) lower and (b) higher magnification of sintered using a pressure of $50 \mathrm{MPa}$, heating rate of $200{ }^{\circ} \mathrm{C} / \mathrm{min}$, sintering temperature of $550{ }^{\circ} \mathrm{C}$, and sintering time of $15 \mathrm{~min}$. 


\section{Materials and Experimental Procedures}

Pure aluminum powder with purity and average particle size of $99.88 \%$ and $33 \mu \mathrm{m}$, respectively, was mechanically milled with 1 wt.\% of $\mathrm{SiC}_{\beta}$ nanopowder having an average particle size of around $50 \mathrm{~nm}$. The milling experiments were carried out using a Fritsch Pulverisette, P5 (Idar-Oberstein, Germany) in argon atmosphere. More details on powder preparation are reported elsewhere [4]. The milled powder was consolidated under ultra-high vacuum of $0.4 \mathrm{hPa}$ using SPS (type HP D 5/2, model SE-607 by FCT system, Rauenstein, Germany). A $20 \mathrm{~mm}$ graphite die was used. In order to study the effect of sintering parameters on the microstructure and properties of the consolidated samples, four sintering parameters were considered in two phases. In the first phase, temperature and sintering time were kept constant $\left(550{ }^{\circ} \mathrm{C}, 5 \mathrm{~min}\right)$ while pressure and heating rate were varied between 20-50 MPa and 100-300 ${ }^{\circ} \mathrm{C} / \mathrm{min}$, respectively, as shown in Table 1. In the second phase, pressure and heating rate were kept constant $\left(50 \mathrm{MPa}, 200{ }^{\circ} \mathrm{C} / \mathrm{min}\right)$ while temperature and sintering time were varied between $500-600^{\circ} \mathrm{C}$ and 5-15 min, respectively, as shown in Table 2.

Table 1. Experimental parameters used to investigate the influence of sintering pressure and heating rate.

\begin{tabular}{ccccc}
\hline SAMPLE & Pressure (MPa) & H.R (K/min) & Temperature $\left({ }^{\circ} \mathbf{C}\right)$ & Time $(\mathbf{m i n})$ \\
\hline $\mathrm{Al}-1 \mathrm{w} \% \mathrm{SiC}-1$ & 20 & 100 & 550 & 5 \\
$\mathrm{Al}-1 \mathrm{wt} \% \mathrm{SiC}-2$ & 35 & 100 & 550 & 5 \\
$\mathrm{Al}-1 \mathrm{wt} \% \mathrm{SiC}-3$ & 50 & 100 & 550 & 5 \\
$\mathrm{Al}-1 \mathrm{wt} \% \mathrm{SiC}-4$ & 20 & 200 & 550 & 5 \\
$\mathrm{Al}-1 \mathrm{wt} \% \mathrm{SiC}-5$ & 35 & 200 & 550 & 5 \\
$\mathrm{Al}-1 \mathrm{wt} \% \mathrm{SiC}-6$ & 50 & 200 & 550 & 5 \\
$\mathrm{Al}-1 \mathrm{wt} \% \mathrm{SiC}-7$ & 20 & 300 & 550 & 5 \\
$\mathrm{Al}-1 \mathrm{wt} \% \mathrm{SiC}-8$ & 35 & 300 & 550 & 5 \\
$\mathrm{Al}-1 \mathrm{wt} \% \mathrm{SiC}-9$ & 50 & 300 & 550 & 5 \\
\hline
\end{tabular}

Table 2. Experimental parameters used to investigate the influence of sintering temperature and time.

\begin{tabular}{ccccc}
\hline SAMPLE & Temperature $\left({ }^{\circ} \mathbf{C}\right)$ & Time (min) & Pressure (MPa) & H.R (K/min) \\
\hline Al- 1 wt $\%$ SiC-1 & 500 & 5 & 50 & 200 \\
Al-1 wt\% SiC-2 & 550 & 5 & 50 & 200 \\
Al-1 wt\% SiC-3 & 600 & 5 & 50 & 200 \\
Al-1 wt\% SiC-4 & 500 & 10 & 50 & 200 \\
Al-1 wt\% SiC-5 & 550 & 10 & 50 & 200 \\
Al-1 wt\% SiC-6 & 600 & 10 & 50 & 200 \\
Al-1 wt\% SiC-7 & 500 & 15 & 50 & 200 \\
Al-1 wt\% SiC-8 & 550 & 15 & 50 & 200 \\
Al-1 wt\% SiC-9 & 600 & 15 & 50 & 200 \\
\hline
\end{tabular}

X-ray diffraction experiments were carried out using a high-resolution X-ray diffractometer (Bruker D8, Madison, WI, USA, with a wavelength $\lambda=0.15405 \mathrm{~nm}$ ). A Tescan Lyra-3 Field Emission Scanning Electron Microscope (FE-SEM, TESCAN, Brno, Czech Republic) with Energy Dispersive 
X-ray Spectroscopy (EDS, Oxford Instruments, Oxfordshire, UK) facility was used to examine the microstructure of the sintered samples and dispersion of $\mathrm{SiC}$ nanoparticles. The density of the sintered samples was determined by Archimedes principle using balance density determination kit Model AG285 of (METTLER TOLEDO GmbH \& weighing Technologies, Greifensee, Switzerland). Microhardness of sintered samples was determined using a digital microhardness tester (Buehler, Lake Bluff, IL, USA). All measurements were conducted by applying the same load of $100 \mathrm{gf}$ for $12 \mathrm{~s}$. The measurement was repeated 10 times at different locations in the sample, and then an average value was taken. Compressive tests were performed using specimens machined to a diameter of $5 \mathrm{~mm}( \pm 0.02 \mathrm{~mm})$ and length of $8 \mathrm{~mm}$ $( \pm 0.02 \mathrm{~mm})$. Instron 3367 testing machine was used for the compression tests at a compression rate of $1 \mathrm{~mm} / \mathrm{min}$.

\section{Conclusions}

A fully dense $\mathrm{Al}-1 \mathrm{wt} \% \mathrm{SiC}$ sample has successfully been consolidated through spark plasma sintering and the influence of sintering parameters on the microstructure and properties was investigated. The uniform distribution of $\mathrm{SiC}$ in the powder was maintained in the sintered sample. It was found that the influence of applied pressure was more pronounced than heating rate while the influence of sintering temperature was more significant than sintering time. Within the range of parameters used, the highest values of the characterized properties were obtained at a sintering temperature of $600{ }^{\circ} \mathrm{C}$, sintering time of $10 \mathrm{~min}$, pressure of $50 \mathrm{MPa}$, and heating rate of $200{ }^{\circ} \mathrm{C} / \mathrm{min}$. Highest values of 108 and $312 \mathrm{MPa}$ were obtained for microhardness and compressive strength, respectively.

\section{Acknowledgments}

The authors would like to acknowledge the support provided by the deanship of scientific research at King Fahd University of Petroleum and Minerals (KFUPM) for funding this work through project IN121008.

\section{Author Contributions}

Nouari Saheb wrote and edited the paper, and contributed in all activities. Ismaila Kayode Aliyu performed the experiments and analyzed the results. Syed Fida Hassan and Nasser Al-Aqeeli contributed in the interpretation and discussion of results.

\section{Conflicts of Interest}

The authors declare no conflict of interest.

\section{References}

1. Bakshi, S.; Lahiri, D.; Agarwal, A. Carbon nanotube reinforced metal matrix composites-A review. Int. Mater. Rev. 2010, 55, 41-64.

2. Miracle, D.B. Metal matrix composites-From science to technological significance. Compos. Sci. Technol. 2005, 65, 2526-2540. 
3. Rosso, M. Ceramic and metal matrix composites: Routes and properties. J. Mater. Process. Technol. 2006, 175, 364-375.

4. Saheb, N.; Aliyu, I.; Hassan, S.; Al-Aqeeli, N. Matrix structure evolution and nanoreinforcement distribution in mechanically milled and spark plasma sintered Al-SiC nanocomposites. Materials 2014, 7, 6748-6767.

5. Rohatgi, P.; Schultz, B. Lightweight metal matrix nanocomposites-stretching the boundaries of metals. Mater. Matters 2007, 2, 16-19.

6. Rostamzadeh, T.; Shahverdi, H.R.; Shanaghi, A.; Shahrabi, T. EIS study of bulk Al-SiC nanocomposite prepared by mechanical alloying and the hot press method. Adv. Mater. Res. 2009, 83-86, 1297-1305.

7. Sadeghian, Z.; Lotfi, B.; Enayati, M.H.; Beiss, P. Microstructural and mechanical evaluation of $\mathrm{Al}-\mathrm{TiB}_{2}$ nanostructured composite fabricated by mechanical alloying. J. Alloy. Compd. 2011, 509, 7758-7763.

8. Suryanarayana, C. Synthesis of nanocomposites by mechanical alloying. J. Alloy. Compd. 2011, 509, S229-S234.

9. Yu, H. Processing Routes for Aluminum Based Nano-Composites. Master Thesis, Worcester Polytechnic Institute, Worcester, MA, USA, 2010.

10. Lan, J.; Yang, Y.; Li, X. Microstructure and microhardness of SiC nanoparticles reinforced magnesium composites fabricated by ultrasonic method. Mater. Sci. Eng. A 2004, 386, 284-290.

11. Yang, Y.; Lan, J.; Li, X. Study on bulk aluminum matrix nano-composite fabricated by ultrasonic dispersion of nano-sized SiC particles in molten aluminum alloy. Mater. Sci. Eng. A 2004, 380, 378-383.

12. Saheb, N.; Qadir, N.U.; Siddiqui, M.U.; Arif, A.F.M.; Akhtar, S.S.; Al-Aqeeli, N. Characterization of nanoreinforcement dispersion in inorganic nanocomposites: A Review. Materials 2014, 7, 4148-4181.

13. Yadav, V. Spark plasma sintering of aluminum matrix composites. Master Thesis, Oklahoma State University, Stillwater, OK, USA, 2011.

14. Saheb, N.; Iqbal, Z.; Khalil, A.; Hakeem, A.S.; Al Aqeeli, N.; Laoui, T.; Al-Qutub, A.; Kirchner, R. Spark plasma sintering of metals and metal matrix nanocomposites: A review. J. Nanomater. 2012, 2012, doi:10.1155/2012/983470.

15. Singla, M.; Dwivedi, D.D.; Singh, L.; Chawla, V. Development of aluminium based silicon carbide particulate metal matrix composite. J. Miner. Mater. Charact. Eng. 2009, 8, 455-467.

16. Saberi, Y.; Zebarjad, S.; Akbari, G. On the role of nano-size SiC on lattice strain and grain size of $\mathrm{Al} / \mathrm{SiC}$ nanocomposite. J. Alloy. Compd. 2009, 484, 637-640.

17. Suryanarayana, C.; Al-Aqeeli, N. Mechanically alloyed nanocomposites. Prog. Mater. Sci. 2013, $58,383-502$.

18. Sadeghi, M.; Mahmoudi, J. Experimental and theoretical studies on the effect of die temperature on the quality of the products in high-pressure die-casting process. Adv. Mater. Sci. Eng. 2012, 2012, doi: $10.1155 / 2012 / 434605$.

19. Borgonovo, C.; Apelian, D.; Makhlouf, M. Aluminum nanocomposites for elevated temperature applications. JOM J. Miner. Metals Mater. Soc. 2011, 63, 57-64. 
20. Rostamzadeh, T.; Shahverd, H. Microstructure study on AL-5\% SiC nanocomposite powders. Iranian J. Mater. Sci. Eng. 2011, 8, 32-39.

21. Benjamin, J.; Volin, T. The mechanism of mechanical alloying. Metall. Trans. 1974, 5, 1929-1934.

22. Gujba, K.A. Development and Characterization of Carbon Nanotubes (CNTs) and Silicon Carbide (SiC) Reinforced Al-Based Nanocomposites. Master Thesis, King Fahd University of Petroleum and Minerals, Dhahran, Saudi Arabia, 2012.

23. Anselmi-Tamburini, U.; Garay, J.; Munir, Z.; Tacca, A.; Maglia, F.; Spinolo, G. Spark plasma sintering and characterization of bulk nanostructured fully stabilized zirconia: Part I. Densification studies. J. Mater. Res. 2004, 19, 3255-3262.

24. Khalil, A. Synthesis and Wear Behaviour of Aluminium 6061 Alloy Reinforced with CNT. Master Thesis, King Fahd University of Petroleum and Minerals, Dhahran, Saudi Arabia, 2012.

25. Al-Aqeeli, N.; Abdullahi, K.; Hakeem, A.; Suryanarayana, C.; Laoui, T.; Saheb, N. Synthesis, characterisation and mechanical properties of SiC reinforced Al based nanocomposites processed by MA and SPS. Powder Metall. 2012, 56, 149-157.

26. Esawi, A.M.K.; Morsi, K.; Sayed, A.; Taher, M.; Lanka, S. Effect of carbon nanotube (CNT) content on the mechanical properties of CNT-reinforced aluminium composites. Compos. Sci. Technol. 2010, 70, 2237-2241.

27. Zhang, J.; Wang, L.; Shi, L.; Jiang, W.; Chen, L. Rapid fabrication of $\mathrm{Ti}_{3} \mathrm{SiC}_{2}-\mathrm{SiC}$ nanocomposite using the spark plasma sintering-reactive synthesis (SPS-RS) method. Scripta Mater. 2007, 56, 241-244.

28. Zhang, J.; Wu, T.; Wang, L.; Jiang, W.; Chen, L. Microstructure and properties of $\mathrm{Ti}_{3} \mathrm{SiC}_{2} / \mathrm{SiC}$ nanocomposites fabricated by spark plasma sintering. Compos. Sci. Technol. 2008, 68, 499-505.

29. Yang, Y.; Li, X. Ultrasonic cavitation-based nanomanufacturing of bulk aluminum matrix nanocomposites. J. Manuf. Sci. Eng. 2007, 129, 252-255.

30. Zhang, J.; Shi, H.; Cai, M.; Liu, L.; Zhai, P. The dynamic properties of $\mathrm{SiC}_{\mathrm{p}} / \mathrm{Al}$ composites fabricated by spark plasma sintering with powders prepared by mechanical alloying process. Mater. Sci. Eng. A 2009, 527, 218-224.

31. El-Daly, A.; Abdelhameed, M.; Hashish, M.; Daoush, W.M. Fabrication of silicon carbide reinforced aluminum matrix nanocomposites and characterization of its mechanical properties using non-destructive technique. Mater. Sci. Eng. A 2013, 559, 384-393.

32. Bathula, S.; Anandani, R.C.; Dhar, A.; Srivastava, A.K. Microstructural features and mechanical properties of $\mathrm{Al} 5083 / \mathrm{SiC}_{\mathrm{p}}$ metal matrix nanocomposites produced by high energy ball milling and spark plasma sintering. Mater. Sci. Eng. A 2012, 545, 97-102.

33. Daly, R.; Khitouni, M.; Kolsi, A.W.; Njah, N. The studies of crystallite size and microstrains in aluminum powder prepared by mechanical milling. Phys. Status Solid. 2006, 3, 3325-3331.

34. Olevsky, E.A.; Kandukuri, S.; Froyen, L. Consolidation enhancement in spark-plasma sintering: Impact of high heating rates. J. Appl. Phys. 2007, 102, doi:10.1063/1.2822189.

35. Bathula, S.; Anandani, R.; Dhar, A.; Srivastava, A. Synthesis and characterization of Al-alloy/ $\mathrm{SiC}_{\mathrm{p}}$ nanocomposites employing high energy ball milling and spark plasma sintering. Adv. Mater. Res. 2012, 410, 224-227. 
36. Ohser-Wiedemann, R.; Martin, U.; Seifert, H.J.; Müller, A. Densification behaviour of pure molybdenum powder by spark plasma sintering. Int. J. Refract. Metals Hard Mater. 2010, 28, $550-557$.

37. Munir, Z.A.; Anselmi-Tamburini, U.; Ohyanagi, M. The effect of electric field and pressure on the synthesis and consolidation of materials: A review of the spark plasma sintering method. J. Mater. Sci. 2006, 41, 763-777.

38. Kwon, H.; Park, D.H.; Park, Y.; Silvain, J.F.; Kawasaki, A.; Park, Y. Spark plasma sintering behavior of pure aluminum depending on various sintering temperatures. Metals Mater. Int. 2010, $16,71-75$.

39. Kwon, H.; Cho, S.; Leparoux, M.; Kawasaki, A. Dual-nanoparticulate-reinforced aluminum matrix composite materials. Nanotechnology 2012, 23, 225704.

40. Khalil, A.; Hakeem, A.S.; Saheb, N. Optimization of process parameters in spark plasma sintering Al6061 and Al2124 aluminum alloys. Adv. Mater. Res. 2011, 328-330, 1517-1522.

41. Saheb, N. Spark plasma sintering of Al6061 and Al2124 alloys. Adv. Mater. Res. 2011, 284, $1656-1660$.

42. Garay, J.E. Current-activated, pressure-assisted densification of materials. Annu. Rev. Mater. Res. 2010, 40, 445-468.

43. Wang, L.; Jiang, W.; Chen, L.; Bai, S. Rapid reactive synthesis and sintering of submicron TiC/SiC composites through spark plasma sintering. J. Am. Ceram. Soc. 2004, 87, 1157-1160.

44. Munoz-Morris, M.; Garcia Oca, C.; Morris, D. An analysis of strengthening mechanisms in a mechanically alloyed, oxide dispersion strengthened iron aluminide intermetallic. Acta Mater. 2002, 50, 2825-2836.

45. Dai, L.; Ling, Z.; Bai, Y. A strain gradient-strengthening law for particle reinforced metal matrix composites. Scripta Mater. 1999, 41, 245-252.

46. Chawla, N.; Shen, Y.-L. Mechanical behavior of particle reinforced metal matrix composites. Adv. Eng. Mater. 2001, 3, 357-370.

47. Casati, R.; Vedani, M. Metal matrix composites reinforced by nano-particles-a review. Metals 2014, 4, 65-83.

48. Aliyu, I.K. Effect of Process Parameters on Microstructure and Properties of Spark Plasma Sintered Al-SiC Nanocomposites. Master Thesis, King Fahd University of Petroleum and Minerals, Dhahran, Saudi Arabia, 2013.

49. Le, G.; Godfrey, A.; Hansen, N. Structure and strength of aluminium with sub-micrometer/micrometer grain size prepared by spark plasma sintering. Mater. Des. 2013, 49, $360-367$.

(C) 2015 by the authors; licensee MDPI, Basel, Switzerland. This article is an open access article distributed under the terms and conditions of the Creative Commons Attribution license (http://creativecommons.org/licenses/by/4.0/). 